\title{
Sodium-Glucose Co-Transporter 2 Inhibitors for Prevention and Treatment of Heart Failure
}

\author{
Nasser Mikhail* \\ Department of Medicine, David-Geffen School of Medicine, United States
}

Submission: October 10, 2019; Published: November 7, 2019

*Corresponding author: Nasser Mikhail, Endocrine Division, Department of Medicine, David-Geffen School of Medicine, Olive View-UCLA Medical Center,14445 Olive View Dr, Sylmar, CA 91342, United States

\section{Abstract}

Background: Sodium-glucose co-transporter 2 inhibitors (SGLT2) are approved medications to treat type 2 diabetes. Recent evidence suggests these agents consistently decrease heart failure hospitalization ( $\mathrm{HFH})$.

Methods: Review of literature (English, French, Spanish) from January 1990 to September 30, 2019. Key words included heart failure, sodium-glucose co-transporter 2, or SGLT2 inhibitors, safety, randomized trials, and meta-analysis. Expert opinions and guidelines are also reviewed.

Results: The use of SGLT2 inhibitors in patients with type 2 diabetes was associated with significant relative reduction in HFH by 30-35\%. This reduction is robust and consistent in patients with various degrees of cardiovascular (CV) risk at baseline. In patients with heart failure and reduced ejection fraction (rEF), dapagliflozin decreased risk of a composite outcome of worsening heart failure or CV death by $26 \%$, as well as secondary outcomes such as HFH by $30 \%$, and death from any cause by $17 \%$. The decrease in risk in these outcomes was similar in patients with or without diabetes. SGLT2 inhibitors were generally well tolerated.

Conclusion: The use of the 3 SGLT2 inhibitors empagliflozin, canagliflozin or dapagliflozin should be considered in all patients with type 2 diabetes at high risk for heart failure. Dapagliflozin should be used in subjects with heart failure and rEF as add-on therapy to reduce HFH and mortality irrespective of presence of diabetes.

Keywords: Heart failure; Sodium-glucose cotransporter 2; Type 2 diabetes; Empagliflozin; Canagliflozin; Dapagliflozin

\section{Introduction}

Heart failure is a common complication of diabetes and is the first cardiovascular event in $14 \%$ of patients with type 2 diabetes [1]. Patients with type 2 diabetes are more than twofold prone to develop $\mathrm{HF}$ than patients without type 2 diabetes, rate ratio being 2.5 [2]. In turn, 35-45\% of patients with chronic HF have type 2 diabetes [3]. Moreover, prognosis of HF in patients with diabetes is worse than in patient without diabetes [4]. SGLT2 inhibitors represent a class of anti-diabetic agents that decrease hyperglycemia independently of insulin by lowering the renal threshold for glucose and therefore increasing urinary excretion of glucose [5]. The main purpose of this review is to summarize the evidence that supports the role of SGLT2 inhibitors in decreasing incidence of $\mathrm{HFH}$ and in treatment of $\mathrm{HF}$ in patients with and without type 2 diabetes.

\section{Evidence from Randomized CV Trials}

Three large randomized double-blind trials were published to examine CV safety of the 3 SGLT2 inhibitors empagliflozin, canagliflozin, and dapagliflozin (Table 1) [6-8]. The primary outcome in these trials was a composite of major adverse CV outcome (MACE) defined as $\mathrm{CV}$ death, non-fatal myocardial infarction or ischemic stroke, whereas one of the secondary outcomes was HFH. Despite the variable baseline CV risk across the 3 trials, the relative reduction in HFH compared with placebo was robust and consistent, ranging from $27 \%$ to $35 \%$. A metaanalysis of the 3 studies estimated the overall risk reduction to be $31 \%$ (hazard ratio $0.69,95 \% \mathrm{CI} 0.61-79$ ) [9]. The decrease in $\mathrm{HFH}$ was similar whether patients had established CV disease at baseline or had only CV risk factors.

Table 1: Hospitalization due to heart failure in major randomized cardiovascular trials of SGLT2 inhibitors in patients with type 2 diabetes.

\begin{tabular}{|c|c|c|c|}
\hline Trial & Empa-Reg [6] & Canavas [7] & Declare [8] \\
\hline SGLT-2 inhibitor & Empagliflozin & Canagliflozin & Dapagliflozin \\
\hline
\end{tabular}


Journal of Endocrinology and Thyroid Research

\begin{tabular}{|c|c|c|c|}
\hline Patients & $\mathrm{n}=7020$, mean age 63, 28\% women & $\mathrm{N}=10142$, mean age 63, 35.8\% women & $\mathrm{N}=17160$, mean age 64, 37.5\% women \\
\hline Patients with *CVD at baseline & $100 \%$ & $65 \%$ & $40 \%$ \\
\hline Patients with heart failure at baseline & $10.10 \%$ & $14.40 \%$ & $10.00 \%$ \\
\hline Follow-up & $\begin{array}{c}\text { Median treatment 2.6 y, median observa- } \\
\text { tion 3.1 y }\end{array}$ & Mean 188 wks, median 126 wk & Median 4.2 y \\
\hline $\begin{array}{c}\text { Relative risk reduction in **HFH } \\
\text { (Hazard ratio, 95\% CI) }\end{array}$ & 0.65 (0.5-0.85), P=0.002 & 0.67 (0.52-0.87), P value not reported & 0.73 (0.61-0.88), P value not reported \\
\hline${ }^{*} \mathrm{CVD}=$ cardiovascular disease; ${ }^{* *} \mathrm{HFH}=$ heart failure hospitalization
\end{tabular}

${ }^{*} \mathrm{CVD}=$ cardiovascular disease; ${ }^{* *} \mathrm{HFH}=$ heart failure hospitalization

Regarding the time course of events, the difference in rates of HFH between the SGLT2 inhibitors and placebo was evident early few months after starting treatment. However, some differences in results exist between the 3 trials. Thus, only empagliflozin was associated with significant reduction in CV and all-cause death [6]. This observation is possibly attributed to the higher proportion of patients (100\% of patients) with established CVD in patients in the empagliflozin trial compared with the 2 trials of canagliflozin and dapagliflozin [7-8]. In addition, a post-hoc analysis of the empagliflozin trial (EMPA-REG Outcome trial) showed that risk of HF re-hospitalization 45-90 days after the first HFH was reduced by approximately $50 \%$ with empagliflozin versus placebo [10].

\section{Evidence from Meta-Analysis of Randomized Trials}

Yang et al [11] performed a network meta-analysis of 91 randomized trials to examine the incidence of HF among different classes of anti-diabetic agents. They found that SGLT2 inhibitors were superior in terms of risk of HF to insulin (odds ratio 0.75 , 95\% CI 0.62-0.91), dipeptidyl peptidase inhibitors (odds ratio $0.68,95 \%$ CI 0.59-0.78), glucagon-like peptide-1 (GLP-1) receptor agonist (odds ratio $0.65,95 \%$ CI 0.54-0.78), and thiazolidinediones (odds ratio $0.46,95 \% 0.27-0.77$ ) [11]. In the subgroup of patients with baseline HF, SGLT2 inhibitors were also superior to metformin in reducing risk of subsequent HF (odds ratio $0.75,95 \%$ CI 0.58-0.95).

\section{Evidence from Real-world Studies}

The benefits of SGLT2 inhibitors on HFH and death were clearly shown in observational studies of real-world practice. The CVD-REAL Study is a large study comparing 154,528 patients with type 2 diabetes initiating SGLT2 inhibitor with similar number of matched patients initiating other glucose lowering drugs across 6 countries [12]. The distribution of exposure time for the various SGLT-2 inhibitors was 53\% for canagliflozin, 42\% for dapagliflozin, and 5\% for canagliflozin. Only 13\% of patients had known CVD at baseline. Compared with other anti-diabetic agents, treatment with SGLT2 inhibitors was associated with $39 \%$ relative risk reduction (hazard ratio $0.61,95 \%$ CI 0.51 0.73 ) in $\mathrm{HFH}$, the primary outcome, and $51 \%$ reduction (hazard ratio $0.49,95 \% 0.41-0.57$ ) in all-cause death, the secondary outcome [12].

This large study adds important information to CV benefits of SGLT2 inhibitors. First, it supports the fact that reduction in HFH is a class effect shared by the 3 SGLT2 inhibitors. Second, it suggests that reduction in HFH and all-cause death extends to relatively young patients with type 2 diabetes (mean age was $57 \mathrm{y})$ at lower CV risk at baseline [12]. In another study using 2 commercial and one Federal data sources, Patorno et al [13] showed that initiation of empagliflozin in real-world practice was associated with $50 \%$ reduction in $\mathrm{HFH}$ as compared with initiation of sitagliptin over a mean follow-up of 5.3 months, hazard ration 0.50 (95\% CI 0.21-0.91). Subgroup analysis by presence of baseline CV disease, history of heart failure, and gender yielded consistent results.

\section{SGLT2 Inhibitors as Treatment for Heart Failure in} Patients with and without Diabetes

Two studies were recently published to evaluate SGLT2 inhibitors as treatment for patients with $\mathrm{HF}$ irrespective of presence of diabetes. The first was a small short-term randomized trial using empagliflozin $10 \mathrm{mg} / \mathrm{d}$ in patients with HF with rEF (mean left ventricular ejection fraction 26\%) [14]. After 12 weeks, significantly greater proportions of patients treated with empagliflozin experienced improvements in $\mathrm{HF}$ symptoms, functional status and quality of life as compared with placebo [14]. Results were the same whether patients had type 2 diabetes $(166$ of $263,62 \%$ ) or no diabetes ( 97 of $263,38 \%$ ). The second study is a landmark randomized trial, the DAPA-HF trial that examined the effect of dapagliflozin in 4,744 patients with $\mathrm{HF}$ and rEF of $40 \%$ or less (Table 2) [15].

Table 2: Overview and main results of DAPA-HF trial in patients with heart failure and reduced ejection fraction with or without diabetes.

\begin{tabular}{|c|c|}
\hline Design & Randomized, double-blind, multi-center, 2 groups \\
\hline Patients & $\mathrm{n}=4744$, mean age 66 y/o, 23\% females, \\
\hline Patients' disease & Heart failure with ejection fraction $\leq 40 \%$, NYHA Class II (67\%), III (32\%), IV (1\%). \\
\hline $\begin{array}{c}\text { Percentage of patients with/without } \\
\text { type 2 diabetes }\end{array}$ & $45 / 55$ \\
\hline Primary outcome & $\begin{array}{c}\text { Composite of worsening heart failure (hospitalization or an urgent visit resulting in intravenous therapy for } \\
\text { heart failure) or cardiovascular death }\end{array}$ \\
\hline
\end{tabular}




\section{Journal of Endocrinology and Thyroid Research}

\begin{tabular}{|c|c|}
\hline Median follow-up & 18.2 months \\
\hline Intervention & Dapagliflozin $10 \mathrm{mg} / \mathrm{d}$ (n=2373), placebo (n=2371) \\
\hline $\begin{array}{c}\text { Risk reduction in primary outcome } \\
\text { with dapagliflozin vs placebo }\end{array}$ & Dapagliflozin $16.3 \%$, placebo $21.3 \%,{ }^{*} \mathrm{HR} 0.74$ (95\% CI, 0.65-0.85), P<0.001 \\
\hline Death from any cause & Dapagliflozin $11.6 \%$, placebo $13.9 \%, \mathrm{HR} 0.83$ (95\% CI 0.71-0.97) \\
\hline Death due to cardiovascular causes & Dapagliflozin 9.6\%, placebo 11.5\%, HR 0.82 (95\% CI 0.69-0.98) \\
\hline Hospitalization due to heart failure & Dapagliflozin 9.7\%, placebo 13.4\% HR 0.70 (95\% CI 0.59-0.83) \\
\hline Worsening renal function & Dapagliflozin 1.2\%, placebo 1.6\%, HR 0.71 (95\% 0.44-1.16) \\
\hline $\begin{array}{c}\text { Percentage of patients with } \geq 5 \text { in- } \\
\text { crease in the KCCQ ** at 8 months }\end{array}$ & Dapagliflozin 58.3\%, placebo 50.9\%, odds ratio, 1.15 (95\% CI 1.01-1.23) \\
\hline $\begin{array}{c}\text { Discontinuation of study drug due to } \\
\text { adverse effects }\end{array}$ & Dapagliflozin 4.6\%, Placebo 4.9\% \\
\hline
\end{tabular}

*HR: hazard ratio; ** KCCQ: Kansas City Cardiomyopathy Questionnaire. Score is from 0 to 100 , with higher score reflects fewer symptoms. An increase in scoring of $\geq 5$ is considered clinically important [15].

The primary outcome was a composite of worsening HF (defined as hospitalization or an urgent visit resulting in intravenous therapy for HF) or cardiovascular death. Over a median follow-up of 18.2 months, the relative reduction in primary outcome in the dapagliflozin group versus the placebo group was $26 \%$ (hazard ratio $0.74,95 \%$ CI $0.65-0.85$, P < 0.001). In addition, there was significant improvement in quality of life at 8 months. Importantly, results in patients without diabetes, who constitute $55 \%$ of the study population, were like those with diabetes. All individual components of the primary outcome were in favor of dapagliflozin. The DAPA-HF provides strong evidence that SGLT2 inhibitors do not only decrease incidence of HF but also may serve as actual therapy for HF and rEF irrespective of presence of diabetes. It was reassuring that no major hypoglycemic episodes were reported among patients without diabetes.

\section{Mechanisms of Cardiac Benefits of SDLT2 Inhibitors}

Mechanisms underlying the reduction in HFH of SGLT2 inhibitors are not fully understood and are currently an area of active research. These mechanisms include changes in arterial stiffness and cardiac oxygen demand, and reduction in the following parameters: serum uric acid, tissue sodium, albuminuria, ambulatory blood pressure, and weight [16]. Regarding the relative importance of these mechanisms, several observations must be considered. First, the fact that reduction in $\mathrm{HFH}$ occurred early within the first few months

after administration of SGLT2 inhibitors suggests that diuresis and natriuresis by these agents may be early mechanisms involved to decrease the after load. Second, it is unlikely that the mild reduction in hemoglobin A1c values (approximately $0.2-0.4 \%$ less than placebo) is a significant factor. This notion is supported by the fact that patients without diabetes had similar magnitude of cardiac benefits [15]. Third, recent data do not suggest a positive inotropic action by SGLT2 inhibitors. Thus, using cardiac magnetic resonance imaging, Verma et al [17] showed amelioration of left ventricular mass index after 6 months of empagliflozin therapy, but no significant effect on ejection fraction [17].

\section{Safety of SGLT2 Inhibitors}

Overall, SGLT2 inhibitors were well-tolerated as reflected by rates of discontinuation due to adverse effects that are like placebo. Likewise, rates of hypoglycemia, acute renal failure are either similar or less than placebo. However, there are 2 adverse effects shared by members of the class. First, genital fungal infections are common, particularly in women (Table 3). These infections are usually mild to moderate in severity and treated with anti-fungal without treatment interruption. Second, diabetic ketoacidosis occurred 2-10 times more frequently with SGLT2 inhibitors than placebo, but the absolute number of events was small. Increased risk of lower limb amputation and fractures previously reported in one large CV trial with canagliflozin [7], were not seen with empagliflozin and dapagliflozin $[6,8]$.

Table 3: Safety of SGLT2 inhibitors in major cardiovascular trials versus placebo.

\begin{tabular}{|c|c|c|c|}
\hline & Empagliflozin [6] & Dapagliflozin [7] & Canagliflozin [8] \\
\hline $\begin{array}{l}\text { Withdrawal due to } \\
\text { adverse effects }\end{array}$ & $17.3 \%$ vs $19.4 \%$ & $8.1 \%$ vs $6.9 \%(\mathrm{P}=0.01)$ & $35 / 1000-y r$ vs $32.8 / 1000-y r, P=0.07$ \\
\hline $\begin{array}{l}\text { Genital fungal infec- } \\
\text { tions }\end{array}$ & $\begin{array}{l}\text { Males: } 5 \% \text { vs } 1.5 \% \text { Females: } \\
10 \% \text { vs } 2.6 \%\end{array}$ & $76 / 8574(0.9 \%)$ vs $9 / 8569(0.1 \%), \mathrm{P}<0.001$ & $\begin{array}{l}\text { Males: } 34.9 / 1000-y r \text { vs } 10.8 / 1000-y r(P<0.001) \text { Fe- } \\
\text { males: } 68.8 / 1000 \text {-yr vs } 17.5 / 1000-y r(P<0.001) \text {. }\end{array}$ \\
\hline Diabetic ketoacidosis & $\begin{array}{c}4 / 4687(0.1 \%) \text { vs } 1 / 2333 \\
(<0.1 \%)\end{array}$ & $\begin{array}{c}27 / 8574(0.3 \%) \text { vs } 12 / 8569(0.1 \%),{ }^{*} \mathrm{HR} \\
2.15(1.1-4.3), \mathrm{P}=0.02\end{array}$ & $0.6 / 1000-\mathrm{yr}$ vs $0.3 / 1000-\mathrm{yr}, \mathrm{P}=0.14$ \\
\hline Amputation & ${ }^{* *} \mathrm{NR}$ & $1.4 \%$ vs $1.3 \%, \mathrm{P}=0.53$ & $6.3 / 1000-\mathrm{yr}$ vs $3.4 / 1000-\mathrm{yr}, \mathrm{P}<0.001$ \\
\hline Fractures & $3.8 \%$ vs $3.9 \%$ & $5.3 \%$ vs $5.1 \%, P=0.59$ & $15.4 / 1000$-yr vs $11.9 / 1000-y r, P=0.02$ \\
\hline
\end{tabular}

${ }^{*} \mathrm{HR}=$ hazard ratio ${ }^{* *} \mathrm{NR}=$ not reported 


\section{Clinical Implications}

Based on the available data discussed above, SGLT2 inhibitors should be considered in the following situations: 1 . To decrease $\mathrm{HFH}$ in patients with type 2 diabetes with risk factors for $\mathrm{HF}$ e.g. older age, obesity, coronary or peripheral artery disease, longer duration of diabetes, hypertension, systolic or diastolic dysfunction, retinopathy or nephropathy [18]. 2. In patients with type 2 diabetes and established CVD, empagliflozin seems to be the SGLT2 inhibitor of choice since it was associated with decreased CV and all-cause mortality in this group of patients in addition to the reduction in risk of HFH. 3. In patients with $\mathrm{HF}$ and $\mathrm{rEF}$ with or without diabetes, dapagliflozin seems the preferred SGLT2 inhibitor based on results of DAPA-HF showing significant reduction in incidence of $\mathrm{HFH}$ and in $\mathrm{CV}$ and all-cause death in this patient population [19].

\section{Conclusion and Current Directions}

Reduction of $\mathrm{HFH}$ by approximately $30 \%$ is a consistent and robust effect of the 3 SGLT2 inhibitors empagliflozin, canagliflozin, and dapagliflozin. The relative risk reduction by these agents emerges few months after starting treatment and is similar in patients with established CV disease and patients with only CV risk factors. In subjects with established HF and rEF, dapagliflozin decreased HFH, CV death and all-cause death. Furthermore, these benefits extend to patients without diabetes. Multiple clinical trials are underway to evaluate the effects of various SGLT2 inhibitors for treatment of patients with HF with preserved and $\mathrm{rEF}$, irrespective of presence of diabetes. The results of these trials will likely change the management of both type 2 diabetes and HF.

\section{References}

1. Shah AD, Langenverg C, Rapsomaniki Edenaxas S, Pujades-Rodriguez $\mathrm{M}$, et al. (2015) Type 2 diabetes and incidence of a wide range of cardiovascular diseases: a cohort study in 1.9 millionpeople. Lancet Diabetes Endocrinol 3(2): 105-113.

2. Nichols GA, Gullion CM, Koro CE, Ephross SA, Brown JB (2004) The incidence of congestive heart failure in type 2 diabetes: an update. Diabetes Care 27(8): 1879-1884.

3. Packer M (2017) Heart failure: the most important, preventable, and treatable cardiovascular complication of type diabetes. Diabetes Care 41(1): 11-13.

4. Van den Berge JC, Constantinescu AA, Boiten HJ, van Domburg RT, Deckers JW, et al. (2018) Short- and long-term prognosis of patients with acute heart failure with and without diabetes: changes over the last three decades. Diabetes Care 41(1): 143-149.

5. Mikhail N (2014) Place of sodium-glucose co-transporter type 2 inhibitors for treatment of type 2 diabetes. World J Diabetes 5(6): 854859 .
6. Zinman B, Wanner C, Fichett D, Bluhmki E, Hantel S, et al (2015) EMPREG OUTCOME Investigators. Empagliflozin, cardiovascular outcomes and mortality in type 2 diabetes. N Engl J Med 373(22): 2117-2128.

7. Neal B, Perkovic V, Mahaffey KW, ZeeuwD, Fulcher G, et al (2017) CANVAS Program Collaborative Group. N Engl J Med 377: 644-657.

8. Wiviott SD, Raz I, Bonaca MP, Mosenzon O, Kato ET, et al (2019) DECLARE-TIMI 58 Investigators. N Engl J Med380: 347-357.

9. Zelniker TA, Wiviott SD, Raz I, Im K, Goodrich IL, et al. (2019) SGLT2 inhibitors for primary and secondary prevention of cardiovascular and renal outcomes in type 2 diabetes: a systematic review and metaanalysis of cardiovascular outcome trials. Lancet 393: 31-39.

10. Fitchett D, Zinman B, Wanner C, Lachin JM, Hanter Z, et al. (2016) Heart Failure outcomes with empagliflozin in patients with type 2 diabetes at high cardiovascular risk: results of the EMPA-REG OUTCOME trial. Eur Heart J 37(19): 1526-1534.

11. Yang D, He X, Liang H, Zhang S, Zhong X, et al. (2019) Comparative outcomes of heart failure among existent classes of anti-diabetic agents: a network meta-analysis of 171,253 participants from 91 randomized trials. Cardiovasc Diabetol 18 (1): 47.

12. Kosiborod M, Cavender MA, Fu AZ, Wilding JP, Khunti K, et al. (2017) Lower risk of heart failure and death in patients initiated on sodium-glucose cotransporter-2 inihibitors versus other glucoselowering drugs. The CVD-REAL Study (Comparative Effectiveness of Cardiovascular Outcomes in New Users of Sodium-Glucose Cotransporter-2 Inhibitors). Circulation 136(3): 249-259.

13. Patorno E, Pawar A, Franklin JM, Najafzadeh M, Deruaz-Luet A, et al. (2019) Empagliflozin and the risk of heart failure hospitalization in routine clinical care. Circulation 139(11): 2822-2830.

14. Nassif ME, Windsor SL, Tang F, Khariton Y, Husain M et al. (2019) Dapagliflozin effects on biomarkers, symptoms, and function status in patients with heart failure with reduced ejection fraction. Circulation 140(18): 1463-1476.

15. McMurray JJV, Solomon SD, Inzucchi SE, Kober L, Kosiborod MN, et al. (2019) Dapagliflozin in patients with heart failure and reduced ejection fraction. $\mathrm{N}$ Engl J Med

16. Lytvyn Y, Bjornstad P, Udell JA, Lovshin JA, Cherney DZ (2017) Sodium glucose cotransporter-2 inhibition in heart failure. Potential mechanisms, clinical implications, and summary of clinical trials. Circulation 136: 1643-1658.

17. Verma S, Mazer CD, Yan AT, Mason T, Garg V, et al. (2019) Effect of empagliflozin on left ventricular mass in patients with type 2 diabetes and coronary artery disease: The EMPA-HEART CardioLink-6 randomized clinical trial. Circulation

18. Dunlay SM, Givertz MM, Aguilar D, Allen LA, Chan M, et al. (2019) Type 2 diabetes mellitus and heart failure: a Scientific Statement from the American Heart Association and Heart Failure Society of America. J Cardiac Failure 140(7): e294-e324.

19. Severovic PM, Petrie MC, Filippatos GS, Anker SD, et al. (2018) Type 2 diabetes mellitus and heart failure: a position statement from the Heart Failure Association of the European Society of Cardiology. Eur J Heart Fail 20: 853-872. 

(CC) (ن) $\begin{aligned} & \text { This work is licensed under Creative } \\ & \text { Commons Attribution 4.0 Licens }\end{aligned}$ BY DOI: $10.19080 / J E T R .2019 .05 .555656$

\section{Your next submission with Juniper Publishers} will reach you the below assets

- Quality Editorial service

- Swift Peer Review

- Reprints availability

- E-prints Service

- Manuscript Podcast for convenient understanding

- Global attainment for your research

- Manuscript accessibility in different formats ( Pdf, E-pub, Full Text, Audio)

- Unceasing customer service

Track the below URL for one-step submission https://juniperpublishers.com/online-submission.php 